\title{
Illustration credits
}

The author and publishers gratefully acknowledge the following individuals and organisations for permission to reproduce copyright materials. The author has made every effort to contact copyright holders, but the publisher would be grateful to hear about any errors or omissions so that they can be rectified in future editions of the book.

Aart Klein/Nederlands fotomuseum - 6.2

Archivio Gallizio, Turin - 5.I, 6.7, 6.8, 6.9

Constant - 6.1, 6.10, 7.1, 7.2, 7.3, 7.4, 7.5, 7.6, 7.8, 7.9, 7.10

FLC/ADAGP, Paris and DACS - 3.1, 3.2, 3.3, 3.4, 3.5, 3.6, 3.7, 3.8, 4.5, $4.6,4.7,4.8,4.9$

Brian Goodey - I.3, I.4

Hertfordshire Archives and Local Studies - 2.5, 2.6

The New York Times Co. $-\mathbf{4 . 2}$

Queen Mary Library, University of London - I.2

Rebel Press, London - 8. I

Marcus Schubert, Toronto - 4.4, 4. I I, 4.I 2 


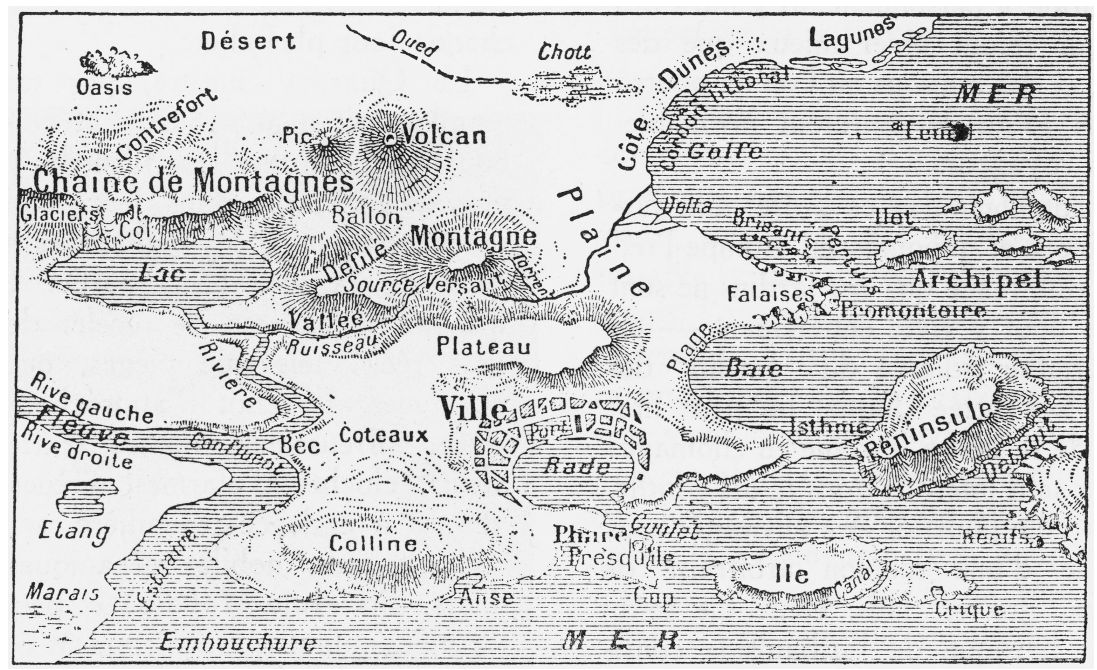

Figure I.I Map from Gilles Ivain (pseudonym for Ivan Chtcheglov), 'Formulary for a new urbanism', Internationale situationniste I (June 1958). 